Tropical Journal of Pharmaceutical Research, June 2009; 8 (3): 209-214

(C) Pharmacotherapy Group,

Faculty of Pharmacy, University of Benin

Benin City, 300001 Nigeria.

All rights reserved.

Research Article

Available online at http://www.tjpr.org

\title{
Altered Endothelium-Dependent Vasoreactivity of Aortic Rings Follows L-Arginine and Potassium Co- Supplementation in Rats
}

\author{
Raymond I Ozolua* and Eric KI Omogbai \\ Department of Pharmacology \& Toxicology, University of Benin, PMB 1154, Benin City 300001, Nigeria
}

\begin{abstract}
Purpose: The use of L-arginine and potassium chloride separately as supplements has been reported to result in altered vascular reactivity. The concentration of either agent used has varied widely and there has been no report on the outcome of combined supplementation with both agents on vascular reactivity. We therefore designed this study to measure thoracic aortic ring reactivity after five-week co-supplementation with $1 \% \mathrm{~L}$-arginine and $0.75 \%$ potassium chloride.

Methods: Endothelium-intact and endothelium-denuded aortic rings obtained from SpragueDawley rats which received the combined supplements were subjected to graded concentrations of carbachol or noradrenaline in organ baths. The maximum responses $\left(E_{\max }\right)$ and the negative logarithm of the concentration producing $50 \%$ of maximum responses $\left(p D_{2}\right)$ were computed as indices of vasoreactivity.

Results: Co-supplementation significantly enhanced the relaxant effects of carbachol irrespective of the status of the endothelium although relaxation was by far higher in endothelium-intact rings. In concentration-response curves obtained with noradrenaline, $\mathrm{E}_{\max }$ and $p \mathrm{D}_{2}$ values were significantly $(P<0.05)$ reduced in endothelium-intact rings obtained from rats which received the supplements. In endothelium-denuded rings, responses to noradrenaline were not significantly different from those of control.

Conclusion: Co-supplementation with the agents enhances the relaxant effect of carbachol independent of the status of the endothelium while attenuating responses to noradrenaline in endothelium-dependent manner. This suggests that oral L-arginine and potassium cosupplementation may possess beneficial vascular effects.
\end{abstract}

Keywords: Potassium chloride, L-arginine, co-supplementation, aortic rings 


\section{INTRODUCTION}

Prevention of hypertensive disease has focused, in recent times, on the use of dietary supplements, several of which are rich in potassium ${ }^{1}$. This has arisen following several studies in humans and animals, which show that potassium supplementation and ingestion of potassium-rich diets reduce blood pressure and the tendency to develop the disease ${ }^{1-3}$. In our previous study, we showed that $0.75 \%$ potassium supplementation in drinking water reduces blood pressure in normotensive animals and blunts responses to some vasoactive drugs ${ }^{4}$. L-arginine as a precursor of nitric oxide has also been widely reported to reduce blood pressure in normotensive humans and animals although the concentrations used vary with the investigators ${ }^{5-7}$.

Several mechanisms have been proposed for the anti-hypertensive effect of potassium. These include increased endotheliummediated dilatation of blood vessels ${ }^{8,9}$, increased activity of vascular superoxide dismutase and $\mathrm{Na}^{+}, \mathrm{K}^{+}$-ATPase enzymes thereby leading to hyperpolarization of blood vessels $^{10,11}$, and reduced response to vasoconstrictors such as angiotensin ${ }^{12}$.

While the possible mechanisms of action of potassium seem to be poorly understood and have generated some controversy, the use of $\mathrm{L}$-arginine seems more defined and better understood. Supplementation with L-arginine (the precursor of the vasodilatory autacoid nitric oxide) has been widely reported to increase the tendency of blood vessels to dilate $^{13,14}$. Inhibition of the synthesis of nitric oxide by administration of L-nitroarginine methyl ester has been known to result in hypertension in several animal studies ${ }^{15,16}$.

There has been no report on the vascular effects of co-supplementation with both potassium chloride $(\mathrm{KCl})$ and $\mathrm{L}$-arginine. We therefore designed experiments in order to study the effects of co-supplementation on the reactivity of aortic rings obtained from
Sprague-Dawley rats and the dependence of these effects on the endothelium.

\section{MATERIALS AND METHODS}

\section{Animals}

Sprague-Dawley rats weighing between 200 and $300 \mathrm{~g}$ were obtained from the animal house of the Department of Physiology, Ambrose Alli University, Ekpoma, Edo State, Nigeria. The animals were allowed two weeks of acclimatization before they were divided into two experimental groups (six animals per group). One group (the control) was given tap water while the second group (treated) received $0.75 \% \mathrm{w} / \mathrm{v} \mathrm{KCl}+1 \% \mathrm{w} / \mathrm{v}$ L-arginine in the tap water. Supplementation was done for a period of 5 weeks since our previous reports on potassium supplementation was for that length of time ${ }^{4,10}$. All animals were housed in standard cages and had free access to pellets (Bendel Feeds and Flour Mills Ltd, Ewu, Nigeria) and the particular drinking fluid. The animals were exposed to natural lighting conditions and were handled according to international protocols for use of animals in experiments (National Institute of Health USA: Public Health Service Policy on Humane Care and Use of Laboratory Animals, 2002; and the 1986 European Convention for the protection of Vertebrate Animals Used for Experimental and other Scientific Purposes) in the absence of a functional local ethical committee on the use of animals. At the end of supplementation, animals were sacrificed under thiopentone sodium (15 mg/kg) anaesthesia.

\section{Measurement of fluid intake}

In order to ascertain that the animals actually drank the fluid which contained the supplements, average daily fluid intake in the groups was measured for the 5 weeks of supplementation. Animals drank from a graduated water bottle and at the same time each day, the decrement in the amount of fluid consumed over $24 \mathrm{~h}$ was measured by 
subtracting the day's reading from that of the previous day.

\section{Isolated aortic ring experiments}

The thoracic aortae were quickly dissected out of the sacrificed animals and placed in physiological salt solution (PSS). The tissues were cleaned of adherent connective tissues and cut into rings of $2 \mathrm{~mm}$ length. In endothelium-denuded rings, denudation was achieved by gently rubbing the intimal layer of the vessel with a wire. The rings were suspended in L-shaped wire loops in $10 \mathrm{ml}$ organ baths containing PSS. The upper loop was attached to a Grass Model FT03 force transducer connected to a Grass Model 7D polygraph (Grass Instruments Co., Quincy, MA, USA). The PSS was made of the following composition (mM/L): $\mathrm{NaCl} 119, \mathrm{KCl}$ 4.7, $\mathrm{NaHCO}_{3}$ 24.9, $\mathrm{KH}_{2} \mathrm{PO}_{4}$ 1.2, $\mathrm{MgSO}_{4}$ 1.2, $\mathrm{CaCl}_{2}$ 1.6, glucose 11.5. The PSS was bubbled throughout with $95 \% \mathrm{O}_{2}-5 \% \mathrm{CO}_{2}$ gas mixture (BOC Gases, Nig. Plc) with the $\mathrm{pH}$ and temperature maintained at 7.4 and $37^{\circ} \mathrm{C}$ respectively. The rings were given a resting force of $1 \mathrm{~g}^{10}$. An equilibration period of 60 min was allowed after which rings were stimulated twice at 15 min intervals with 100 $\mathrm{mM} \mathrm{K} \mathrm{K}^{+}$. Aortic tissue viability was closely monitored within 6-hour period of experiments. This was ascertained by the observation that force produced by $100 \mathrm{mM}$ $\mathrm{K}^{+}$for each ring was reproducible within this period.

Rings from both groups were exposed to cumulative concentrations of noradrenaline ranging from $1 \times 10^{-10} \mathrm{M}$ to $1 \times 10^{-4} \mathrm{M}$. Vasorelaxant effects of carbachol were studied by precontracting the rings with noradrenaline at a concentration producing $75 \%$ of maximal noradrenaline-induced contraction obtained from pilot study $\left(1 \times 10^{-6}\right.$ $\mathrm{M}$ for control and $1 \times 10^{-7} \mathrm{M}$ for the treated). Contractile responses from the pilot studies were $75.2 \pm 4.7 \%$ and $74.3 \pm 5.5 \%$ for $1 \times 10^{-}$ ${ }^{6} \mathrm{M} N A$ (control) and $1 \times 10^{-7} \mathrm{M}$ NA (treated) respectively. This was followed by the addition of the relaxant; after steady contraction had been established (timedependent control experiments showed that the precontraction induced by noradrenaline remained stable for the duration of the concentration-response tests).

\section{Drugs}

Noradrenaline and carbachol were obtained from Sigma (UK) and were prepared fresh each day by dissolving in distilled water. Larginine and $\mathrm{KCl}$ for supplementation were obtained from BDH chemicals (UK) and were prepared once a week. All other chemicals and reagents were of analytical grade and were obtained from either of Sigma, May \& Baker or BDH chemicals.

\section{Statistics}

Aside from daily fluid intake in the two groups which is presented as means, all other data are presented as mean \pm SEM (standard error of the mean) and $n$ represents the number of rats from which aortic rings were taken. $E_{\max }$ (the maximum response by aortic rings) are presented either as contractile force $(\mathrm{mg})$ produced by rings exposed to noradrenaline, or as percentage of maximum relaxation response to carbachol following noradrenaline precontraction. Comparison of $E_{\max }$ and $p D_{2}$ (negative log of the concentration producing $50 \%$ contractile response to noradrenaline) values were made by use of Student's t-test. In all cases, $P<0.05$ was taken as indicating statistically significant difference between compared data.

\section{RESULTS}

The daily fluid intake by the animals as measured for 35 days shows fluctuating but insignificantly different patterns of consumption between the two groups (Fig. 1). Mean daily volume of the fluid consumed by the control group was $133.0 \pm 2.2 \mathrm{ml}$ and $130.0 \pm 2.0 \mathrm{ml}$ for the L-arginine $+\mathrm{KCl}$ cosupplementation group. 


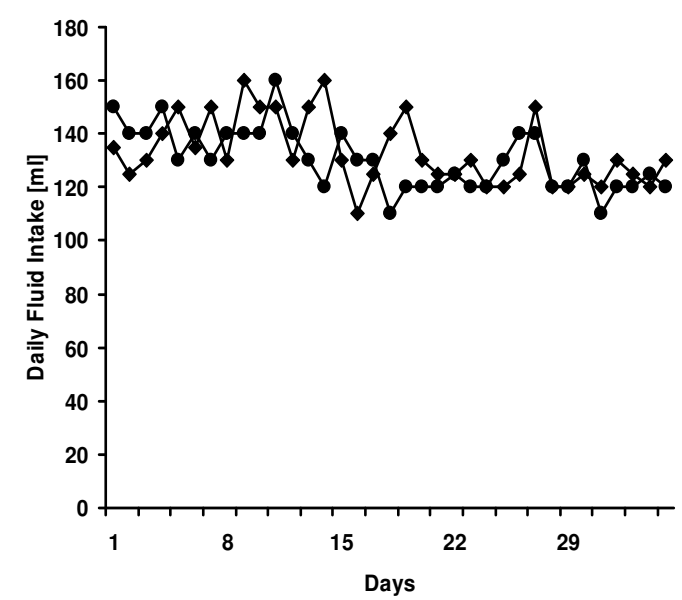

Figure 1: Daily fluid intake by rats on tap water (control $\bullet$ ) and $\mathrm{L}$-arginine $+\mathrm{KCl}$ co-supplemented fluid (treated $\bullet$ ). Means of daily fluid intake for the 5 weeks are not significantly different between the groups. $n=6$ per group.

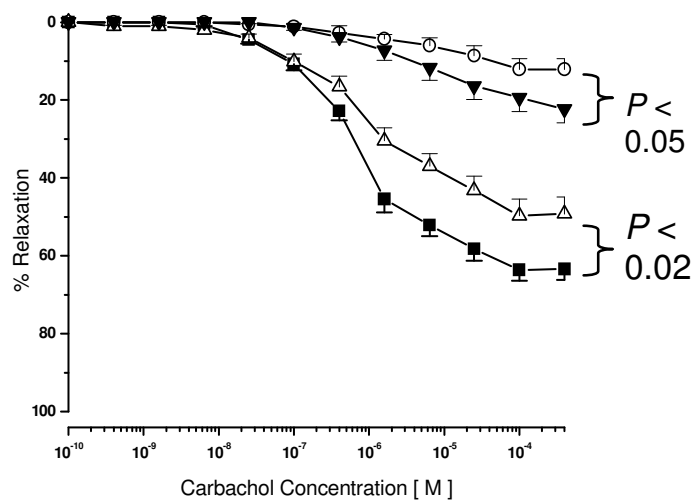

Figure 2: The relaxant effect of carbachol on aortic rings from rats given tap water (control) or L-arginine and $\mathrm{KCl}$ co-supplemented fluid for 5 weeks. There is significant difference in the maximum relaxant effect irrespective of the status of the endothelium. ( $\mathbf{a})$, treated endotheliumintact; (०), control endothelium-denuded; $(\Delta)$, control endothelium-intact; $(\boldsymbol{\nabla})$, treated endothelium-denuded. $n$ $=6$ per group.

Co-supplementation with $\mathrm{L}$-arginine and $\mathrm{KCl}$ significantly enhanced the relaxation of endothelium-denuded aortic rings to effective concentrations of carbachol (Fig. 2). There was increase in the $E_{\max }$ compared to values in control $(22.3 \pm 3.6$ versus $12.1 \pm 2.7 \%)$. Treatment also significantly altered the maximum relaxation to carbachol in endothelium-intact aortic rings (63.4 \pm 2.8 versus $49.2 \pm 4.3 \%$ ).

Endothelium-intact aortic rings obtained from rats which received the supplements showed significantly attenuated responses to noradrenaline (Fig. 3). $E_{\max }$ values were significantly lower in endothelium-intact rings from the treated group compared to the control: $1315.5 \pm 106.2$ versus $1690.1 \pm 68.1$ $\mathrm{mg}(P<0.05)$. Similarly, the $p \mathrm{D}_{2}$ values were significantly lower in the endothelium-intact rings from the treated group than the control $(7.0 \pm 0.1$ versus $7.4 \pm 0.1, P<0.05)$. Although endothelium-denuded rings from the treated group showed lower $\mathrm{E}_{\max }$ and higher $p D_{2}$ values than rings obtained from the controls, these values were not significantly different. The respective values are $2069.5 \pm 80.1$ versus $2356.8 \pm 228.0 \mathrm{mg}$ $\left(E_{\max }\right)$ and $8.0 \pm 0.2$ versus $7.8 \pm 0.1\left(p D_{2}\right)$.

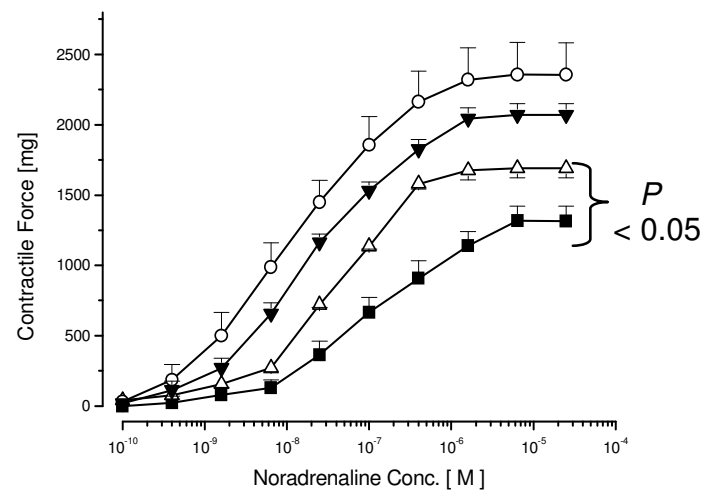

Figure 3: Effects of noradrenaline on aortic rings from rats given tap water (control) or L-arginine and $\mathrm{KCl}$ cosupplementation (treated) for 5 weeks. Supplementation significantly attenuated the responses of endotheliumintact aortic rings compared to control. The difference between maximum contractile responses of endotheliumdenuded rings from both groups is not significant. (घ), treated endothelium-intact; (o), control endotheliumdenuded; $(\Delta)$, control endothelium-intact; $(\boldsymbol{\nabla})$, treated endothelium-denuded. $n=6$ per group.

\section{DISCUSSION}

The combination of $1 \% \mathrm{~L}$-arginine and $0.75 \%$ $\mathrm{KCl}$ as supplements in drinking fluid of rats has been shown in the present study to alter vascular reactivity to noradrenaline and 
carbachol. In rats which received the supplements, responses of endotheliumintact aortic rings to noradrenaline were attenuated while there was enhanced relaxation by aortic rings to carbachol irrespective of the status of the endothelium.

In our previous study we showed that while supplementation with $0.75 \% \mathrm{KCl}$ for five weeks did not affect acetylcholine-induced relaxation in endothelium-intact aortic rings, it significantly enhanced acetylcholine-induced relaxation in endothelium-denuded rings ${ }^{17}$. Similarly, responses to vasoconstrictors such as noradrenaline and $5-\mathrm{HT}$ were attenuated in aortic rings from potassium-supplemented rats. $^{17}$ Decreased vasoconstriction to noradrenaline and enhanced relaxation to acetylcholine have also been reported in DOCA-salt hypertensive rats which were placed on $0.8 \%$ L-arginine supplementation ${ }^{18}$. Consequently, the present data suggest that the combined supplements further enhanced carbachol-induced relaxation in an endothelium-independent manner.

This enhanced carbachol-induced relaxation is possibly due to the fact that basal nitric oxide production was increased by the increased provision of the precursor Larginine although serum and urinary Larginine levels were not measured. Several workers have found that supplementation with L-arginine enhances relaxant action of acetylcholine while improving haemodynamics in human and animal experiments ${ }^{7,18,19}$. Nitric oxide itself causes relaxation through the cyclic GMP pathway while also facilitating the opening of potassium channels with the resultant vascular smooth muscle cell hyperpolarisation $^{20}$. Similarly, several reports have suggested that potassium supplementation enhances endotheliumdependent relaxations, increased vascular activity of superoxide dismutase and $\mathrm{Na}^{+}, \mathrm{K}^{+}$ATPase enzymes and reduced vascular reactivity to pressor agents ${ }^{8-12}$. Although membrane potentials were not measured in the present study, it seems that vascular smooth muscle cell hyperpolarisation may only be a part mechanism since in our previous report potassium channel blockade with tetraethylammonium only partially reversed the enhanced relaxant effect of levcromakalim and sodium nitroprusside in aortic rings obtained from potassiumsupplemented rats ${ }^{17}$.

Although several protocols and concentrations have been used each for Larginine and $\mathrm{KCl}$, previous workers have indicated that the concentrations used in the present study are well tolerated by the animals. For example the animals become adapted to the increased potassium load after weeks of supplementation ${ }^{21}$. In the case of L-arginine, concentrations far in excess of what has been used in the present study have been reportedly well tolerated ${ }^{22}$. The ability of the animals to tolerate the supplements is accentuated by the facts that fluid consumption was not significantly different in the two groups and that there were no obvious signs of toxicity.

\section{CONCLUSION}

Combining potassium chloride and L-arginine as supplements enhances carbachol-induced relaxation in an endothelium-independent manner while blunting vasoconstriction by noradrenaline in endothelium-intact aortic rings. These are beneficial vascular effects in the non-pharmacologic prophylaxis of hypertension and its sequelae.

\section{ACKNOWLEDGEMENTS}

The authors are grateful to Miss Miriam Ezeanuna who assisted with the work and to BOC Gases Nigeria Plc for offering a discount on the cost of $\mathrm{O}_{2}-\mathrm{CO}_{2}$ gas mixture.

\section{REFERENCES}

1. Gu D, He J, Wu X, Duan X, Whelton PK. Effect of potassium supplementation on blood pressure in Chinese: a randomized placebo-controlled trial. J Hypertens 2001; 19: 1325-1331. 
2. He FJ, Markandu ND, Colhart R, Barron J, MacGregor GA. Effect of short-term supplementation of potassium chloride and potassium citrate on blood pressure in hypertension. Hypertension 2005; 45: 571 574.

3. Naismith DJ, Braschi $A$. The effect of low-dose potassium supplementation on blood pressure in apparently healthy volunteers. Br J Nutr 2003; 90: 53-60.

4. Omogbai EKI, Ozolua RI, Ebeigbe, AB. Effects of potassium adaptation on blood pressure and pressor responses in normotensive and renal hypertensive Wistar rats. Methods Find. Clin Pharmacol 2005; 27: 5-10.

5. Moura JR, Sass N, Guimaraes SB, Vasconcelos PR, Mattar, R, Kulay L. Jr. Effects of L-arginine oral supplementation in pregnant spontaneously hypertensive rats. Acta Cir Bras 2006; 21: 192196.

6. de la Riva IJ, Rosón MI, Vega GW, Speziale N, Albornoz LE, Palumbo EL, Ferrero AJ, Damiano PF. Effect of oral L-arginine administration for three weeks in two kidneytwo clip hypertensive rats. Arch Physiol Biochem 2000; 108: 415-421.

7. Facchinetti F, Saade GR, Neri I, Pizzi C, Longo M, Volpe $A$. L-arginine supplementation in patients with gestational hypertension: a pilot study. Hypertens Pregnancy 2007; 26: 121130.

8. Tolvanen J-P, Makynen $\mathrm{H}, \mathrm{Wu} X$, Hutri-Kahonen $\mathrm{N}$, Ruskoaho H, Karjala K, Porsti I. Effects of calcium and potassium supplements on arterial tone in vitro in spontaneously hypertensive rats. $\mathrm{Br} J$ Pharmacol 1998; 124: 119-128.

9. Raij L, Luscher TF, Vanhoutte PM. High potassium diet augments endothelium-dependent relaxations in Dahl rat. Hypertension 1988; 12 : 562-567.

10. Ozolua RI, Omogbai EKI, Ebeigbe AB, Asagba SO. Increased superoxide dismutase and $\mathrm{Na}^{+}, \mathrm{K}^{+}$ATPase activities in aortic strips from potassium-adapted rats: implication for altered vascular reactivity. Comp Biochem Physiol Part C 2003; 135: 61-65.

11. Dolson GM, Wesson DE, Androgue HJ. Vascular relaxation mediates the antihypertensive effect of high potassium: $A$ role for enhanced vascular $\mathrm{Na}^{+}, \mathrm{K}^{+}$-ATPase activity. Hypertension 1995; 13: 1433-1439.

12. Campbell WB, Schmitz JM. Effect of alterations in dietary potassium on pressor and steroidogenic effects of angiotensin II and III. Endocrinology 1978; 103: 2098-2104.

13. Ray EC, Landis ME, Miller VM. Effects of dietary Larginine on the reactivity of canine coronary arteries. Vasc Med 1999; 4: 211-217.

14. Oner G, Bilgen I. L-arginine-induced changes in the characteristics of endothelial relaxation. $J$ Basic Clin Physiol Pharmacol 2001; 12: 77-90.

15. Gerová M. Nitric oxide-compromised hypertension: facts and enigmas. Physiol Res 2000; 49: 2735.

16. van Dokkum RP, Jacob HJ, Provost AP. Blood pressure and the susceptibility to renal damage after unilateral nephrectomy and LNAME-induced hypertension in rats. Nephrol Dial Transplant 2000; 15: 1337-1343.

17. Ozolua RI, Omogbai EKI, Ebeigbe AB. Altered vascular reactivity in isolated aortic rings from potassium-adapted Wistar rats. Intl $J$ Pharmacol 2006; 2: 193-200.

18. Laurant $P$, Demolombe B. Berthelot Dietary Larginine attenuates blood pressure in mineralocorticoid-salt hypertensive rats. Clin Exp Hypertens 1995; 17:1009-1024.

19. Nagaya $N$, Uematsu $M$, Oya $H$, Sato $N$, Sakamaki $F$, Kyotani S, Ueno K, Nakanishi N, Yamagishi M, Miyatake K. Short-term oral administration of L-arginine improves hemodynamics and exercise capacity in patients with precapillary pulmonary hypertension. Am J Respir Crit Care Med 2001; 163: 887-891.

20. Brayden JE. Potassium channels in vascular smooth muscle. Clin Exp Pharmacol Physiol 1996; 23: 1069-1076.

21. Giebisch G. Physiology of potassium metabolism. In: Whelton KP, Whelton A, Walker GW, (eds). Potassium in cardiovascular and renal medicine. New York: Marcel Dekker Inc, 1986: pp 3-12.

22. Wu G, Bazer FW, Cudd TA, Jobgen WS, Kim SW, Lassala $A, L i P$, Matis $J H$, Meininger CJ, Spencer TE.Pharmacokinetics and safety of arginine supplementation in animals. J Nutr 2007; 137: 1673S-1680S. 